\title{
Virginia Woolf y la nueva amenaza bélica: del silencio narrativo a la voz de la sibila
}

\author{
Francisco José CORTÉS VIECO \\ Departamento de Filología Inglesa II \\ Universidad Complutense de Madrid \\ francort@pdi.ucm.es
}

\begin{abstract}
RESUMEN
La Gran Guerra alertó a muchos escritores de la posible réplica de un nuevo derramamiento de sangre en décadas posteriores. El fascismo, el rearme militar y la endeble paz en Europa durante los años treinta confirmaron este temor y borraron el silencio narrativo de Virginia Woolf, quien articulará su voz de sibila para prevenir o confirmar la inminente guerra. Mientras que esta escalada de violencia abrazaba ideales patrióticos o ambiciones totalitarias, la exclusión de la mujer de la vida pública imposibilitaba su mediación conciliadora ante cualquier contienda. «Three Guineas» formulará el utópico tándem entre pacifismo y feminismo como antídoto ante las amenazas (auto)destructivas en la alianza entre belicismo y patriarcado. Sin embargo, el pesimismo premonitorio del ensayo sugiere que la distopia sociopolítica de ese momento histórico entorpecía la administración de esta panacea a la humanidad, y profetiza el pánico del pueblo inglés ante los bombardeos nazis durante la Segunda Guerra Mundial.
\end{abstract}

Palabras clave: patriarcado, militarismo, fascismo, patriotismo, feminismo, pacifismo.

\section{Virginia Woolf and the new threat of war: from narrative silence to the voice of the sybil}

\begin{abstract}
World War I alerted many writers to the probable replica of another bloodshed in coming decades. The rise of fascism, the rearmament and the weak entente between the Western nations during the 1930s confirmed this fear and obliterated Virginia Woolf's narrative silence. She eventually articulated her voice as a sybil to prevent or confirm the advent of the impeding war. Whereas this escalating violence embraced patriotic ideals or totalitarian ambitions, the exclusion of women from public spheres nullified their conciliatory efforts to avoid another carnage. «Three Guineas» formulates the utopian tandem between pacifism and feminism as the ideal antidote against the institutional alliance between militarism and patriarchy that jeopardized the world's peace. However, the pessimism within this essay suggests that the sociopolitical dystopia in those historical times hindered the successful administration of such a remedy to humankind, and foreshadowed the panic of English people with the Nazi air raids during World War II.
\end{abstract}

Keywords: patriarchy, militarism, fascism, patriotism, feminism, pacifism. 
Quand [la force] s'exerce jusqu'au bout, elle fait de l'homme une chose au sens le plus littéral, car elle en fait un cadavre. Il y avait quelqu'un, et, un instant plus tard, il n'y a plus personne [...] Un homme desarmé et nu surlequel se dirige une arme devient cadavre avant d'être touché'. Simone Weill (2003:19-20).

La Primera Guerra Mundial (1914-1918) no solo anunció un nuevo tipo de conflicto bélico modernizado por el uso de trincheras, ingeniería militar y una sofisticada tecnología, fruto de la segunda Revolución Industrial, para fabricar de nuevas armas, sino que también golpeó las creencias, los valores y verdades absolutas de ambos bandos por su intensidad destructiva. Asimismo, alertó las plumas de muchos escritores que creían que un nuevo derramamiento de sangre podría repetirse en el futuro cercano. El silencio narrativo de la escritora Virginia Woolf (1882-1941) en la Inglaterra de entreguerras en torno a este reciente pasado no debe interpretarse únicamente como una estrategia literaria de escapismo modernista. La transversalidad, la elipsis narrativa y la subjetividad que penetra en los recovecos del cerebro y luego emana de sus obras Mrs Dalloway (1925) y To The Lighthouse (1927) parecerían eludir la hostilidad sociopolítica en Europa, aunque no el derrumbamiento de la fe en el ser humano ni la constatación del trauma colectivo por culpa de la prevalencia del daño marcial en la vida cotidiana de los supervivientes y sus familias. En la primera novela, el recuerdo de destrucción y muerte asedia la mente de Septimus, un excombatiente enfermo que sufre de shellshock, o neurosis de la guerra. No obstante, también afecta de forma oblicua a Clarisa Dalloway, una mujer de la alta sociedad y mediana edad, aparentemente despreocupada y frívola, o retumba en la atmósfera londinense como un llanto mudo y un eco no tan lejano: «This late age of the world's experience had bred in them all, all men and women, a well of tears. Tears and sorrows; courage and endurance, a perfectly upright and stoical bearing» (Woolf 1992a:10). Mientras tanto, la obra trinitaria To the Lighthouse textualiza la guerra con el capítulo «Time Passes», un interludio afónico entre presencias y ausencias, luces y oscuridad, entre un verano idílico para la familia Ramsay anterior al conflicto y el intento de recuperación anímica de sus supervivientes tras el mismo. Por un lado, la victoria de 1918 no será un trofeo de gloria épica ni garante de una paz duradera para Gran Bretaña. Por otro, las descomunales bajas humanas y materiales serán objeto de duelo nacional o de traumática indiferencia de todo un pueblo durante más de una década. Pero los acontecimientos históricos de los años treinta, marcados por el fascismo en Italia o Alemania, la Guerra Civil Española (19361939), el rearmamento y el debilitamiento de la concordia entre las naciones occidentales, serán ominosas señales de alerta que no hablarán por sí solas. La inminente

1 «Cuando [la fuerza] se ejerce hasta el final, esta convierte al hombre en una cosa, o en sentido literal, en un cadáver. Antes había alguien y, en un instante, ya no hay nadie [...] Un hombre desarmado y desnudo hacia el que se dirige un arma es un cadáver, incluso antes de ser tocado por ella» (traducción propia). 
amenaza contra la entente europea provocará que el academicismo inglés de entreguerras abandone su apoliticismo y que asistamos a la evolución en la carrera literaria de Virginia Woolf, desde el silencio a la militancia, cuando, por encargo, articule su voz de sibila sobre la temática de la hostilidad bélica en «Three Guineas» (1938), que no es una llamada para luchar contra el fascismo sobre Europa, sino la guerrilla de esta autora para resistir y vencer a cualquier tipo de violencia. Este ensayo se construye en torno a una carta ficticia en la que Woolf reflexiona ante la pregunta de un eminente abogado londinense: ¿qué podemos hacer para prevenir la guerra? Este formato epistolar será la excusa perfecta para entrelazar esta problemática con la desigualdad de género y polemizar, en sus tres secciones, sobre el acceso de la mujer a la educación universitaria y a profesiones remuneradas, así como a influir en la vida pública, principalmente en la cultura y la política. Por debajo del optimismo subyacente en este proyecto utópico que engarza pacifismo y feminismo, el presente artículo pretende descubrir el pesimismo de una Virginia Woolf que diagnostica la naturaleza cíclica de todo conflicto bélico al estar sustentado en estructuras patriarcales inquebrantables, y que profetiza el advenimiento de la Segunda Guerra Mundial (1939-1945) ante la inviabilidad, o la lejanía temporal, de su antídoto contra la destrucción de vida, riquezas e ilusiones del individuo y las naciones.

Cualquier guerra es una crónica histórica de masacre humana y de cataclismos urbanos o paisajísticos. Para Robert Pujade, los conflictos armados desfiguran el espacio físico que no podrá evocar más la nostalgia de tiempos pasados, sino que memorizará las heridas de la ruina provocada por el hombre y reaviva un sentimiento de desolación ante semejante derribo (2014:5). Mientras tanto, Louis Crocq sostiene que el apilamiento de cadáveres es un espectáculo que traumatiza la mente de quien los observa y que suscitaría empatía, pena, horror, indignación o rebelión (1999:199). Conseguiría resquebrajar el equilibrio mental del individuo, desconcertarle y crearle dudas sobre la supuesta armonía en su mundo, sus virtudes e ideales (199). Con precisión quirúrgica y efectismo retórico, Virginia Woolf sustenta su manifiesto antimilitarista de «Three Guineas» en fotografías de escombros y cuerpos muertos o mutilados de la población civil que desnudan la barbarie de la Guerra Civil Española ${ }^{2}$ y presagian su posible reproducción más allá de los Pirineos, tan solo un año antes de la ocupación alemana de Polonia, que fue el detonante de la Segunda Guerra Mundial. Según la autora, estas instantáneas que muestran los dos ejes fundamentales de destrucción física y humana son: «not an argument; they are simply a crude statement of fact addressed to the eye» (1992b:165). Si una imagen vale más que mil palabras, Holly Henry indica que los periódicos ingleses durante la contienda ibérica solían censurar o se negaban a publicar estas pruebas gráficas

${ }^{2}$ Uno de los acontecimientos de la Guerra Civil Española con mayor impacto internacional en los medios de comunicación europeos, y que pudo influir en «Three Guineas», fue el ataque que destruyó la ciudad vasca de Guernica en abril de 1937, inmortalizado por el lienzo de Pablo Picasso. Este bombardeo de fuerzas alemanas e italianas ayudó a la causa franquista contra tropas de ideología izquierdista en Vizcaya. 
de la atrocidad militar, porque dichos medios de comunicación debían fomentar sentimientos de patriotismo y nacionalismo en sus lectores para mantener el espíritu belicista (2003:145). En consonancia, el ensayo de Woolf propone una medida para prevenir la guerra: «protecting culture and intellectual liberty»(1992b:277), al mismo tiempo que denuncia que ambas se «prostituyan» por dinero y sean siervas de intereses patriarcales, como es nutrir el patriotismo violento y autoritario de los pueblos. Con el fin de dinamitar todo ideal de gloria u orgullo chovinista que aún residía en el imaginario colectivo de la nación inglesa sobre la guerra, el ensayo de Virginia Woolf recurre a su cara más descarnada y objetiva, poblada de hogares destruidos, familias rotas y cadáveres, a menudo de niños, para concienciar a la población británica sobre la brutalidad y la destructividad de la guerra. Según Susan Sontag, la originalidad de la obra es mostrar lo que políticamente incorrecto en la guerra: que la máquina de matar tiene género, es un juego masculino que satisface al hombre y disgusta a la mujer (2003:3). Además, su creadora detectaría que nuestro fallo es no tener imaginación y no darnos cuenta de cuál es la realidad de la guerra, sobre todo porque no somos «monstruos amorales», sino como Woolf insiste «una clase culta» capaz de discernir las situaciones con ecuanimidad (Sontag 2003:6). Sin embargo, recurrir en este ensayo a «la verdad» ocultada por una prensa al servicio del poder del Estado gracias a estas instantáneas sería un arma de doble filo. Utilizadas en solitario por una autora demasiado sofisticada como ella, no servirían para disuadir a sus compatriotas de gestar una atmósfera hostil, de callada beligerancia entre Gran Bretaña y las naciones europeas en 1938 que presagiaría la inminente tormenta marcial. Si no fueran tan solo el preámbulo de su argumentación antimilitarista para persuadir al lector, estas imágenes inundarían el corazón de sus conciudadanos con odio y deseos de justicia por los crímenes cometidos contra civiles mediante el uso masivo de bombas, fusiles o tanques. La escritora modernista necesitará, pues, desarrollar su teoría antibelicista con más recursos.

«Three Guineas» resume la situación de la política internacional en 1938, con el apogeo de regímenes fascistas propagados por toda Europa, desenmascara los horrores de la guerra con fotografías, y su autora, como sibila moderna, pretendería prevenir sus posibles réplicas en la siguiente década, por culpa de la naturaleza cíclica de la misma y la incapacidad del ser humano para aprender de sus errores: «it seems as if there were no progress in the human race, but only repetition» (1992b:248-249). Sin embargo, este ensayo, sobre todo, investiga por qué las naciones luchan y destapa una obviedad desapercibida hasta entonces: son los hombres, y no las mujeres, los que combaten en el frente. Con vehemencia e ironía, Virginia Woolf adopta el papel de «hija de un hombre culto» para acusar a la relación de retroalimentación entre belicismo y patriarcado a la hora de perpetuar la omnipresencia histórica de la desigualdad de género y los conflictos armados: «to fight has always been the man's habit, not the woman's [....] the vast majority of birds and beasts haven been killed by you, not by us; and it is difficult to judge what we do not share» (1992b:159). Este alegato que exonera de culpa a la población femenina de toda contienda pasada, identifica que la sed de violencia del hombre es vocacional y aval de su virilidad: «war is a profession; a source of happiness and excitement; and it is also an outlet for manly qualities, without which men would deteriorate» (1992b:160). Pero para Woolf, este tándem 
sinérgico de violencia que garantiza la supremacía masculina se alía, además, con la religión, la biología o el Estado: «They said that God was on their side, Nature was on their side, Law was on their side, and Property was on their side» (1992b:248). En su invectiva contra el lavado de cerebro al pueblo llevado a cabo por las instituciones patriarcales, como el gobierno o la prensa, la autora acusará al clero de colaboracionismo con la propaganda militarista de la nación. Como agnóstica, reflexionará sobre lo poco «cristiano» que es que la Iglesia Anglicana defienda el honor de la patria de la amenaza del enemigo extranjero, y no la protección de vidas humanas o el fomento de la concordia entre países hermanos. Sin embargo, resulta aún más significativa la conexión que Woolf establece entre el atractivo de la guerra para el hombre y sus impecables uniformes de soldado, la disciplina castrense, las medallas y la coreografía sinfónica de las marchas militares: «your finest clothes are those that you wear as soldiers [...] to impress the beholder with the majesty of the military office, partly in order through [your] vanity to induce young men to become soldiers» (1992b:180). La autora recurriría a lo anecdótico y lo aparentemente insignificante para resaltar hasta qué extremo los conflictos armados son absurdos e irracionales, porque no salvan vidas, sino que engordan los egos de hombres que, desde niños, son educados para desear convertirse en héroes de guerra y reafirmar así su masculinidad. No obstante, las dos grandes guerras del siglo XX desmoronarán este mito y la glamurosa parafernalia colorista a su alrededor. En ellas, el soldado no podrá demostrar su bravura y pericia en el combate cuerpo a cuerpo contra el enemigo, mientras que el inmovilismo en las trincheras y la tecnología armamentística democratizarán la muerte de todos los combatientes: torpes o capaces, cobardes o valientes.

Marie-Luise Gättens explica que la distribución desigual de poder entre hombre y mujer fue un constituyente básico de las doctrinas fascistas en la Alemania de los años treinta: las esposas que trabajaban para ganar un sueldo adicional al de sus maridos eran «las culpables» de las altas tasas de desempleo (1995:7). El nazismo suponía, pues, un genocidio sociocultural contra toda influencia femenina en esferas públicas y privadas, que contribuía al odio y la segregación entre ambos sexos, así como a la homogeneización ideológica del país germano. Sin embargo, el enemigo totalitario (Adolf Hitler, Francisco Franco o Benito Mussolini) no sería un monstruo satánico localizado solo en Alemania, España e Italia, respectivamente, sino que también estaría cómodamente instalado en la Gran Bretaña post-victoriana, anclada aún en la tradición patriarcal, el conservadurismo, la misoginia y el nacionalismo durante los años anteriores a la Segunda Guerra Mundial, y que incitaría a la violencia contra la mujer o contra otras naciones europeas:

'Nature has done well to entrust the man with the care of his family and the nation. The woman's world is her family, her husband, her children, and her home's. One is written in English, the other in German. But where is the difference? Are they not both saying the same thing? Are they not both the voices of Dictators, whether they

${ }^{3}$ Este fragmento del que Virginia Woolf se hace eco en «Three Guineas» procedería de un mitin de Adolf Hitler, pronunciado en 1936 y recogido por el periódico inglés Sunday Times (Shiach 1992: 429). 
speak English or German, and are we not all agreed that the dictator when we meet him abroad is a very dangerous as well as a very ugly animal? And he is not here among us, raising his ugly head, spitting his poison, small still, curled up like a caterpillar on a leaf, but in the heart of England (1992b:229).

Las palabras de Virginia Woolf son translúcidas al proclamar que el fascismo desafía fronteras marítimas allende la Europa continental, y que sería el progenitor de «dictadores en suelo patrio» $\mathrm{u}$ hombres en los hogares ingleses, aparentemente protectores e inofensivos. Encerrada en la domesticidad del hogar, en prisiones inglesas ${ }^{4}$, en campos de concentración nazis o enterrada viva en una cueva, la escritora inglesa comparará el autoritarismo de tiranos del siglo XX con la tragedia griega de Antígo$n a^{5}$ para demostrar que, desde hace varios milenios, se ejerce una misma violencia con diferentes víctimas. Sugerirá que el exterminio de la pluralidad y la diferencia es una misma atrocidad cometida por el hombre y dirigida, sin distinción, contra el colectivo femenino, los judíos u otras minorías étnicas o religiosas, los disidentes y todo el que ame la paz. La siguiente afirmación de Woolf reniega de cualquier sentimiento nacionalista o vínculo emocional con Inglaterra: «As a woman I have no country. As I woman I want no country. As a woman my country is the whole world» (1992b:313). Susan Stanford Friedman denomina esta declaración como baluarte del «cosmo-feminismo o feminismo cosmopolita» de la autora británica, que repudiaría su nacionalidad y ansiaría convertirse en ciudadana del mundo debido a la coyuntura prebélica de los años treinta (2013:23, 25). Movida por el pacifismo, este alegato demuestra su indiferencia con respecto al sentimiento patriótico y que la guerrilla de sexos en la vida privada y pública es también el pilar sobre el que se sustenta la política nacional e internacional de los países europeos. La lección aprendida del pasado reciente, e integrada en la ideología pacifista de Virginia Woolf para impedir su réplica en los años treinta, rechazaría el lema horaciano «dulce et decorum est pro patria mori» ${ }^{6}$ de la propaganda bélica de Gran Bretaña que condujo a miles de jóvenes ingleses a alistarse en 1914, con entusiasmo, a las tropas del frente occidental en Francia y a morir de forma absurda y fútil en las trincheras durante la Primera Guerra Mundial ${ }^{7}$.

Loretta Stec sostiene que, en «Three Guineas», Virginia Woolf ofrece el proyecto utópico del feminismo organizado para combatir el carácter distópico de la

${ }^{4}$ En referencia a la opresión e intolerancia sufrida por los movimientos de las sufragistas de principios del siglo XX, como Emmeline Pankhurst, que fueron a menudo detenidas e ingresadas en calabozos ingleses.

${ }_{5}^{5}$ Hija de Edipo y Yocasta, Antígona se rebela contra la autoridad de su tío Creonte, rey de Tebas, al querer enterrar a su hermano, considerado por este monarca como un traidor que no merece honores fúnebres. La joven será condenada por el dictador Creonte a ser enterrada en viva para castigar su desobediencia.

${ }^{6}$ Procedente del latín, esta expresión se traduce como: «es dulce y honroso morir por la patria».

${ }^{7}$ Los versos de los Poetas de la Guerra como Wilfred Owen y Siegfried Sassoon que lucharon en la Primera Guerra Mundial, o el bestseller autobiográfico Testament of Youth (1933) de Vera Brittain, una enfermera que perdió a sus seres queridos en el combate, mostraron la cruda realidad de guerra contra cualquier ideal patriótico: los soldados malgastaban su juventud en el frente y estaban abocados a una muerte inevitable. 
modernidad en los años treinta, una década debatida entre el militarismo y el pacifismo, el fascismo y el comunismo, el nacionalismo y un afán de internacionalización, la religiosidad y la secularización de la sociedad (2001:179). Una vez mostrada la cruda realidad de la guerra mediante fotografías en este ensayo, después de identificar a los agentes beligerantes en ambos bandos y desvelar las motivaciones del tándem entre militarismo y patriarcado, la escritora modernista formulará la panacea de pacifismo y feminismo de las mujeres para combatir la amenaza del totalitarismo y la escalada de violencia en la próxima década de los cuarenta: «they are fighting the tyranny of the patriarchal state as you are fighting the tyranny of the Fascist state» (1992b:303). Indudablemente, esta obra de Woolf atesora cualidades utópicas, rebosantes de optimismo, a la hora de encarar la problemática bélica. Según Helen Maxson, el ostracismo público sufrido por la mujer, libre de egocentrismo y egoísmo, habilita al colectivo femenino a subvertir la tradición militarista para lograr la paz y la justicia social (1999:151). Pero el carácter quimérico e ilusorio de este proyecto reconocido por Woolf: «the dream of peace, the dream of freedom» (1992b:365) aleja a esta fantasía de paz e igualdad de escenarios de realismo y objetividad que garanticen la materialización de un mundo mejor en un futuro cercano: sin guerras y con igualdad de género. Entraría, por tanto, en escena la voz de la sibila que cantaría las bondades de los instrumentos de prevención de la violencia y la tiranía masculina: la mediación de la mujer en la actualidad sociopolítica y planes educativos renovados; pero profetizaría que este ambicioso plan es impracticable en Europa durante los años treinta. Por tanto, ratifica su visión pesimista ante la inminente Segunda Guerra Mundial que se avecinará sobre Europa un año después de la publicación de este ensayo. En relación a la educación universitaria, Virginia Woolf puntualiza que la tradición académica fomenta el uso de las armas como medida de autoridad y seguridad general a la hora de proteger vidas humanas y la propiedad de sus tierras y pertenencias. La educación debía, pues, experimentar una reforma sustancial para frenar la predisposición, no congénita sino socialmente aprendida, del hombre por la guerra: «You must educate the young to hate war. You must teach them to feel the inhumanity, the beastliness, the insupportability of war» (1992b:182). Asimismo, Woolf no duda en brindar su alternativa docente: «[it] should teach the arts of human intercourse; the art of understanding other people's lives and minds $[\ldots]$ it should explore the ways in which mind and body can be made to cooperate; discover what new combinations make good wholes in human life» (1992b:200). Esta poética de hermandad y empatía emocional glorificada por la autora, aplicada a toda área del conocimiento y contraria a cualquier propaganda armamentística: «refuse to teach any art or science that encourages war» (1992b:204) debería, además, estar acompañada de otros cambios sociales y de género para prevenir la guerra y garantizar una paz duradera: el acceso de la mujer y las clases bajas a la universidad, al trabajo remunerado fuera del hogar, a la igualdad salarial y las mismas opciones profesionales que los hombres y las clases medias y altas: «by protecting the rights of the individual; by opposing dictatorship; by ensuring the democratic ideals of equal opportunity for all « (1992b:301). En definitiva, el antibelicismo y el feminismo de Virginia Woolf en su ensayo aboga, ante todo, por la igualdad de todos los ciudadanos, la tolerancia y la paz social con- 
tra el autoritarismo dictatorial en el uso de la violencia en conflictos internacionales $o$ en el funcionamiento interno de las naciones.

Pese al carácter teórico de su utopía de justicia universal desde lo doméstico hasta las relaciones internacionales, Woolf ofrece ejemplos prácticos, aunque probablemente inviables o impopulares, para prevenir la guerra: que el colectivo femenino no trabaje en la industria armamentística mientras que sus maridos y hermanos combaten, disuadirles para que no se alisten voluntariamente al frente, despreciar la noción de patriotismo o la idea de seguridad que ofrece el soldado británico: «if he adds that he is fighting to protect her body, she will reflect upon the degree of physical protection that she now enjoys when the words 'Air Raid Precaution'8 are written on blank walls» (1992b:311-312). Este afán por demostrar que el hombre es incapaz de proteger a la mujer sería una profecía ominosa de Woolf quien, paradójicamente, vivió en primera persona las alarmas antiaéreas sobre Inglaterra y recibió la noticia de que su hogar londinense había sido destruido por aviones alemanes? Solo dos años después de «Three Guineas», en plena Segunda Guerra Mundial con la amenaza de las bombas nazis sobre su cabeza y unos meses antes de su suicidio en marzo de 1941, recogería estas ideas en su ensayo «Thoughts on Peace in an Air Raid»:

The Germans were over this house last night and the night before that. Here they are again. It is a queer experience, lying in the dark and listening to the zoom of a hornet which may at any moment sting you to death. It is a sound that interrupts cool and consecutive thinking about peace. Yet it is a sound - far more than prayers and anthems - that should compel one to think about peace. Unless we can think peace into existence we — not this one body in this one bed but millions of bodies yet to be born will lie in the same darkness and hear the same death rattle overhead (Woolf 2016).

El terror en la oscuridad a la espera de la irrupción de explosivos desde su refugio en la campiña inglesa, bien sea simbólicamente el túnel de la muerte o una cavidad intrauterina, no dinamita su visión de «luz»: la paz como única vía de salvación para el ser humano, no el boato religioso ni himnos patrióticos. Sus convicciones antimilitaristas en situaciones de riesgo extremo en 1940 son férreas e invariables con respecto al preludio bélico de tensa calma en su ensayo de 1938, y están indisolublemente ligadas a la igualdad de género: las mujeres, sin fusiles o bombas, debe defenderse por sí solas buscando otras armas para combatir la guerra. Aunque en «Thoughts on Peace in an Air Raid» Virginia Woolf identifique el totalitarismo

8 «Air Raid Precautions» (ARP), o precauciones antiaéreas, fue una organización británica ideada antes del estallido de la Segunda Guerra Mundial y puesta en funcionamiento durante la misma para proteger la vida de los civiles ingleses, especialmente en Londres, asediados por la amenaza de las bombas nazis.

9 Debido a los orígenes judíos de su marido Leonard y a la terrible amenaza nazi, Virginia Woolf se instaló en su casa de Rodmell, en el condado de Sussex, y abandonó las ofícinas de la editorial Hogarth Press y su hogar de Londres, destruidos posteriormente durante los bombardeos alemanes de 1940. 
inherente al papel público del hombre en la sociedad, ya sea el «diablo» germano o el «protector» inglés, muestra empatía hacia todo el colectivo masculino sin importarle su origen y sin precedentes en su propia militancia feminista. Por un lado, reconoce que hombres y mujeres viven la misma experiencia de indefensión y encarcelamiento, ya sea un soldado desde un avión de combate en los cielos o su amada en su hogar terrestre amenazado por una bomba. Y por otro, insta a hijas, hermanas y esposas a tender la mano a sus padres, hermanos o maridos para batallar juntos contra la fiebre armamentística y el absurdo privilegio de morir por la patria:

We must help the young Englishmen to root out from themselves the love of medals and decorations. We must create more honourable activities for those who try to conquer in themselves their fighting instinct, their subconscious Hitlerism. We must compensate the man for the loss of his gun. (Woolf 2016)

Esta supuesta hermandad entre hombres y mujeres podría ser también una burla sardónica de una autora, conocida por su ironía, contra el ideal de hombría en peligro de extinción si la causa pacifista prosperara. Aunque Virginia Woolf parezca tender la mano al «enemigo» varón o a reírse de su masculinidad amenazada por la paz en 1940, dos años antes en «Three Guineas», propone insubordinarse y desvincularse del universo patriarcal que el hombre ha construido durante siglos en torno a su supremacía: «We can best help you to prevent war not by joining your society but by remaining outside your society but in co-operation [to] assert 'the rights of allall men and women» (1992b:366). Marie Luise Gättens interpreta que la autora declina entrar de forma activa en las instituciones políticas contemporáneas con el objetivo de transformarlas y hacer que funcionen mejor, porque no comparte los intereses de estas organizaciones y porque, al final, las mujeres siempre acaban apoyando las estructuras de poder masculino (1995:20-21). Este proyecto antisistema y separatista para prevenir la guerra que Woolf articula como conclusión a su ensayo, es una utopía que nace para morir ya que, en la situación sociopolítica de finales de los años treinta, no se cumplían las condiciones necesarias para que el colectivo femenino destruyera endémicas estructuras androcéntricas de poder y pudiera construir una alternativa democrática, que incluyera al hombre en su renovador orden social. Ante la inevitabilidad de la guerra y la desigualdad de género en ese momento histórico, la voz de sibila de Virginia Woolf puede solo plantar la semilla para que pacifismo y feminismo, de la mano, salgan victoriosos en un futuro incierto: «A common interest unites us; it is one world, one life [...] Both houses will be ruined, the public and the private, the material and the spiritual, for they are inseparably connected» (1992b:365). A modo de despedida, sus palabras resaltan que solo hay una misma violencia tiránica (la que el hombre ejerce sobre la mujer en su hogar o la que el dictador extranjero impone sobre países vecinos o hermanos), y que esta solo puede ser exterminada gracias a la convergencia de dos esferas de la vida (la pública y la privada) que han estado separadas desde siempre.

En esta misma línea de negatividad profética, John Whittier-Ferguson halla que las dos últimas novelas de Virginia Woolf: The Years (1937) y Between The Acts (1941), reflejan el pesimismo de su autora sobre la inevitabilidad de la contienda, y 
concluyen en silencio al ser imposible describir el mundo nuevo que se avecina o muy probable que las palabras sigan contando la misma historia porque nuestra realidad cambió demasiado poco (2011:246-247). Gracias a la objetividad fotográfica de la destrucción humana y material en una España dividida, «Three Guineas» coincide en que la guerra no es el pasado de Occidente, sino también el presente y el futuro. Aunque la escritora modernista confirme la naturaleza cíclica de las contiendas armadas y que es imposible que el hombre deje de reproducir su instinto dictatorial y errores atávicos en el uso de las armas a lo largo de la historia, igualmente detecta las condiciones distópicas de la modernidad que no permiten soñar con un mundo mejor a corto plazo. El ensayo de Woolf imagina que podemos salvar a la humanidad de un futuro incierto ante la amenaza cierta de la guerra y el fascismo, gracias al revulsivo del tándem entre feminismo y pacifismo; pero al mismo tiempo, augura un nuevo derramamiento de sangre porque el totalitarismo de cualquier contienda, basado en el patriotismo y el ideal masculino de heroicidad bélica, cuenta con un gran aliado: el patriarcado, sustentado en patrones masculinos de autocracia en ámbitos académicos, profesionales y militares. Mientras galopen juntos, no se podrá alcanzar la utopía de un nuevo ordenamiento sociopolítico, nacional e internacional, estructurado en el pacifismo y la igualdad de género, desde las relaciones entre hombre y mujer hasta la diplomacia paneuropea. Si atendemos a las razones expuestas en su nota de suicidio dirigida a su marido, Virginia Woolf se ahogó el 28 de marzo de 1941 en el río Ouse porque estaba aterrorizada ante la inminente reaparición de la enfermedad mental en su vida. Sin embargo, Vera Brittain correlaciona el fracaso humano de esta escritora con el fracaso internacional ante el retorno ominoso de la guerra: «Her end was perhaps a kind of protest, the most terrible and effective that she could make, against the real hell that international conflicts create for the artists» (1988:69-70). Sea o no su muerte voluntaria un acto de desobediencia civil contra el belicismo y la discriminación de la mujer durante años de bombardeos nazis sobre Inglaterra, las palabras introductorias de Simone Weill ayudan a intuir que Woolf pudo sentir un pánico más feroz que la locura que precipitara su silencio definitivo: que la violencia subordine al alma, le robe su humanidad (si no puede evitar el sufrimiento ajeno) y le convierta, pues, en un cadáver antes del impacto de una bomba. Ochenta años después, sigue resonando el eco de la sibila de la autora de «Three Guineas»: nuestra realidad es igual y, al mismo tiempo, diferente. El tándem entre pacifismo y feminismo es, todavía hoy en día, una utopía. El mundo sigue asediado por totalitarismos y amenazas de guerra, la igualdad de género es nominal, pero no real, mientras que la violencia y el miedo siguen siendo los enemigos de la libertad y la paz.

\section{Referencias bibliográficas}

BRITTAIN, Vera (1988): «Letter to Peace Lovers» (24 de abril de 1941), in Testament of a Peace Lover: Letters from Vera Brittain, Winifred \& Alan Eden-Green (eds.), pp. 69-70. London: Virago.

CROCQ, Louis (1999): Les traumatisques psychiques de guerre. Paris: Odile Jacob. 
GÄTtens, Marie-Luise (1995): Women Writers and Fascism: Reconstructing History. Gainesville, Florida: The University Press of Florida.

HENRY, Holly (2003): Virginia Woolf and the Discourse of Science: The Aesthetics of Astronomy. Cambridge: Cambridge U.P.

MAXSON, Helen (1999): «Virginia Woolf’s Evolving Optimism in The Waves, The Years, and Three Guineas». The Midwest Quarterly 33, 2:151-167.

PUJADE, Robert (2014): «Preface», in L'esthétique des ruines dans la photographie de guerre, Marcel Fontini (ed.), pp. 5-7. Paris: L'Harmattan.

SHIACH, Morag (1992): «Explanatory Notes to Three Guineas», in A Room of One's Own \& Three Guineas, Morag Shiach (ed.), pp. 427-433. Oxford: Oxford U.P.

SonTAG, Susan (2003): Regarding the Pain of Others. New York: Picador.

STANDFORD FRIEDMAN, Susan (2013): «Wartime Cosmopolitanism: Cosmofeminism in Virginia Woolf's Three Guineas and Marjane Satrapi's Persepolis». Tulsa Studies in Women's Literature 32, 1:23-52.

STECT, Loretta (2001): «Dystopian Modernism vs Utopian Feminism: Burdekin, Woolf, and West Respond to the Rise of Fascism», in Virginia Woolf and Fascism: Resisting the Dictator's Seduction, Merry Pawlowski \& Jane Marcus (eds.), pp. 178-193. London: Palgrave.

WEILL, Simone (2003): Simone Weill's The Iliad or the Poem of Force/ L'iliade ou le poème de la force (ed. crítica), James P. Holoka (trad.). New York: Peter Lang.

WhitTIER-FERGUSON, John (2011): «Repetition, Remembering, Repetition:Virginia Woolf's Late Fiction and the Return of War». Modern Fiction Studies 57, 2:230-253.

Woolf, Virginia (1992a): Mrs. Dalloway. Stella McNichol (ed.). London: Penguin.

(2016): «Thoughts on Peace in an Air Raid». The Death of the Moth and Other Essays. Adelaide, Australia: University of Adelaide. [en línea]. En: https://ebooks.adelaide.edu.au/w/ woolf/virginia/w91d/chapter28.html.[Consulta: 30/05/2016].

- (1992b): «Three Guineas», in A Room of One's Own \& Three Guineas, Morag

Shiach (ed.), pp. 153-367. Oxford: Oxford U.P. 